\title{
El Desarrollo local como Salida Profesional para los Titulados en Ciencias laborales: Una Aproximación a la Realidad Valenciana ${ }^{1}$
}

Ricard Calvo Palomares*

\section{RESUMEN:}

Los estudios universitarios forman profesionales bajo unas directrices concretas basadas en la "presunta y futura" ubicación de estos en el mercado de trabajo. Desde hace unos años cada vez más el mercado de trabajo ha sido el escenario en el que de manera continuada han ido apareciendo nuevas actividades y empleos, muchas de las que con el paso de tiempo se han convertido en profesiones de futuro. El presente artículo se centra en una de estas nuevas actividades, la del Empleo y el Desarrollo Local, realizando un estudio en el ámbito de la Comunitat Valenciana sobre la ubicación profesional de los egresados en Ciencias Laborales en este campo.

\section{Palabras Clave:}

Ciencias laborales; perfilesprofesionales; salidas profesionales; empleo; desarrollo local.

\section{ABSTRACT:}

University studies are professionals under specific guidelines based on "alleged and future" location of these on the labour market. In recent years increasing labour market has been

* Departamento de Sociología y Antropología Social. Universidad de Valencia • Ricardo.Calvo@uv.es

1. El presente artículo aporta en alguno de sus apartados datos e informaciones obtenidos en un proyecto de investigación en curso en el Departamento de Sociología y Antropología Social de la Universitat de València, que pretende analizar el papel clave que desarrollan los Agentes de Empleo y Desarrollo Local en la aplicación, desarrollo y ejecución de las políticas activas de empleo sobre el territorio. 
the scenario in which continuously have appeared new jobs and businesses, many of which over time have become occupations of the future. This article focuses on one of these new activities, the Employment and Local Development, a study in the area of the Valencia on the professional placement of graduates in Science Labour in this area.

\section{KEYWORDS:}

Occupational science; profiles, career, employment, local development.

\section{INTRODUCCIÓN}

Hablar en la actualidad de estudios universitarios conlleva necesariamente hacer una referencia expresa a su futura inserción en el mercado de trabajo. Es por ello que el mundo académico ha iniciado un proceso de redefinición de las competencias necesarias para el desarrollo laboral de cada una de las profesiones. A su vez, cada una de las titulaciones universitarias, ha concretado -en base a estudios de la realidad laboral de sus egresados- las actividades en las que sus titulados pueden actuar en un futuro laboral, en las que aplicar las competencias mencionadas anteriormente. A estas salidas laborales se las ha llamado perfiles profesionales.

El interés concreto del presente artículo será la reflexión y estudio de las salidas o perfiles profesionales de los egresados en Ciencias Laborales ${ }^{2}$. Referirnos a salidas profesionales para los estudios de Ciencias Laborales tradicionalmente ha tenido una equivalencia inmediata con la asesoría jurídico-laboral. Nóminas, contratos, derecho del trabajo o de la seguridad social han sido el campo de trabajo habitual de una titulación muy orientada hacia la aplicación de estos conceptos en el mundo de la empresa. La diplomatura en Graduado Social -posteriormente en Relaciones Laborales- ha sido un claro ejemplo del proceso de especialización profesional de una actividad laboral, aspecto que ha constituido en sí mismo una dificultad, ya que ha encasillado y limitado a sus egresados hacia esa actividad, casi como única salida profesional posible.

Sin embargo, la evolución misma de la titulación y de sus egresados, tanto desde el punto de vista del ajuste realizado dentro del entorno académico como desde la paulatina concreción externa de sus posibles ubicaciones laborales, ha posibilitado que en la actualidad nos refiramos a titulados en Ciencias Laborales, sea sinónimo

2. A lo largo del texto del artículo nos referiremos al titulado en Ciencias Laborales, entendido este en sentido amplio, por tanto, englobará a todos aquellos diplomados en Relaciones Laborales o diplomados Graduados Sociales, a aquellos diplomados en Relaciones Laborales o diplomados Graduados Sociales que completaron su formación académica con el segundo ciclo de Ciencias del Trabajo como a aquellos Licenciados en Ciencias del Trabajo que provenientes de otras titulaciones distintas a las Relaciones Laborales dedican su labor profesional a ellas. 
de profesionales de las relaciones laborales y los recursos humanos, que pueden abarcar todas y cada una de las dimensiones que estos puedan tener. La proyección profesional de estos técnicos ha sido la de ir creciendo, ello ha permitido el acceso a puestos, funciones y actividades que hasta el momento parecían reservados para otras titulaciones. El proceso de valoración y prestigio interno-externo que han experimentado estos estudios ha posibilitado que estemos hablando hoy por hoy de técnicos formados para afrontar un abanico muy amplio de posibilidades laborales.

\section{LO LABORAL COMO CUESTIÓN DE ESTUDIO}

\section{UN LARGO PROCESO PARA EL RECONOCIMIENTO UNIVERSITARIO}

Las relaciones emanadas de la interacción entre el factor capital y el factor trabajo han sido desde tiempo a, una de las cuestiones que más han preocupado al ser humano. Su estudio y adecuado tratamiento se han convertido en materia de interés a lo largo de los tiempos, que ante la no existencia de unas "ciencias oficiales" encargadas del estudio natural de las mismas, las ciencias vinculadas tradicionalmente con ellas han sido muchas, desde la Economía, el Derecho o la Sociología, hasta otras como la Psicología, la Ingeniería de Procesos o la Organización de Métodos y Tiempos de trabajo.

En este sentido, las dos últimas décadas han supuesto la consolidación de unos estudios que centrados en estas relaciones emanadas del trabajo poco a poco han posibilitado la aparición de titulados especialistas en estas materias. La existencia en la actualidad de un campo específico de estudio de y desde las ciencias laborales, es el resultado de un largo proceso de reivindicación de la existencia de unas ciencias específicas de lo laboral. Un claro ejemplo de este triunfo ha sido la aparición en la década de los dos mil de los estudios superiores en Ciencias del Trabajo ${ }^{3}$, lo que suponía el reconocimiento expreso a estos nuevos profesionales de un estatus universitario igual al de titulaciones como Derecho, Económicas o Psicología

La evolución histórica de los estudios vinculados con las relaciones del trabajo en nuestro país ha ido muy ligada a la evolución propia que ha tenido el trabajo como tal. De hecho sus orígenes históricos estuvieron muy parejos al ordenamiento, establecimiento y desarrollo de la legislación social, laboral y de protección social, centrando su objeto principal en la legislación laboral y la organización del trabajo. Aunque legalmente la profesión de Graduado Social no aparece hasta el año 1951,

3. El R.D. 1592/1999 de 15 de octubre (B.O.E. 23 de octubre) estableció el título universitario oficial de Licenciado en Ciencias del Trabajo y las directrices generales propias de los planes de estudios.

4. Con la reforma promovida con el plan Bolonia, la tradicional diferenciación existente entre diplomaturas y licenciaturas desaparecerá, pasando todos los estudios universitarios a denominarse como Grados. 
sus orígenes históricos están unidos al Instituto de Reformas Sociales (1903), crisol de la intervención planificada de Estado en materia laboral.

La Escuela Social de Madrid (1925), en dependencia del Consejo de Cultura Social del Ministerio, supuso el punto de partida de los estudios superiores en Ciencias laborales. La actuación de esta primera escuela ubicada en Madrid, supondría de modo paulatino el marco ideológico y la concreción inicial de los estudios, que con posterioridad se irían extendiendo por todo el país; Barcelona, Zaragoza y Valencia en 1929 o Sevilla en 1930. Esta primera etapa dio como resultado que en la década de los cincuenta se reconociera oficialmente la profesión y se reglamentara socialmente, siendo la institucionalización de la profesión años después con el Decreto de 22 de diciembre de 1960, que crea los Colegios Oficiales de Graduados Sociales, reconociendo en su artículo segundo que dicha profesión consistía en el asesoramiento, gestión y representación, sin necesidad de apoderamiento especial, de las empresas y particulares en cuantos asuntos sociales les fueren encomendados.

Los sucesivos planes asignados a estos estudios, permitieron en la década de los ochenta la implantación de los estudios de Graduado Social (Plan de estudios de 1980), que reconocía por primera vez el carácter de enseñanza especializada, y su condición de título universitario. Tenían por objeto el estudio de las cuestiones que interesan a la mejora o bienestar de las clases obreras tanto agrícolas como industriales, y que afectan a las relaciones entre capital y trabajo.

Aún así, el cambio más importante se sitúa a partir de la publicación del Real Decreto 1429/1990 de 26 de octubre, que estableció tanto el título oficial de Diplomado en Relaciones Laborales -dirigido a sustituir el espacio ocupado hasta entonces por el título de Graduado Social Diplomado-, como las directrices generales propias a las que debían sujetarse los planes de estudios conducentes a la obtención de dicho título. En dicha reforma, dirigida al conocimiento interdisciplinar e integral del mundo del trabajo, se modificaron de forma significativa los contenidos docentes, y se amplió el perfil profesional de estos estudios planteándose como objetivo formativo el "proporcionar una formación adecuada en las bases teóricas y en las técnicas de la organización del trabajo y de la gestión de personal; así como de la ordenación jurídica del trabajo y de la Seguridad Social"s. Objetivo amplio, que abría un abanico de salidas profesionales a estos Diplomados en el mundo de la empresa, en el ejercicio libre de la profesión y en las Administraciones Públicas (Aneca, 2005).

5. La Universitat de València lo define como "el técnico al que se le proporcionan conocimientos sobre las relaciones laborales en la empresa y se estudian todos los aspectos como conflictos laborales, convenios colectivos, organización del trabajo, gestión del personal, ordenación jurídica y laboral de los trabajadores, condiciones de trabajo, etcétera." Se trata por tanto de un técnico de empresa, que debe dominar diversas y variadas disciplinas que interactúan entre sí. 
Sin embargo, la necesidad de dar un contenido formativo adecuado a aquellos nuevos perfiles y a los cambios sustantivos que se habían ido produciendo en el mundo del trabajo en las últimas décadas, situaron a estos estudios ante una nueva necesidad derivada de las limitaciones objetivas que la diplomatura presentaba. El R.D. 1592/1999 de 15 de octubre estableció el título universitario oficial de Licenciado en Ciencias del Trabajo y las directrices generales propias de los planes de estudios, fijando como objetivo formativo del propio título, el de procurar una formación adecuada de carácter interdisciplinar en el campo del trabajo humano en su doble vertiente organizativa y relacional.

Tabla 1. Evolución Histórica De la Titulación En Ciencias laborales PRIMERA ETAPA (1925).

LAS ESCUELAS SOCIALES: EL MARCO IDEOLÓGICO DE SUS ORÍGENES

SEGUNDA ETAPA (1950).

LA REGLAMENTACIÓN SOCIAL Y LA CREACIÓN DE LA PROFESIÓN

TERCERA ETAPA (1980).

LOS PRIMEROS PLANES DE ESTUDIO. LA DIPLOMATURA EN GRADUADO SOCIAL

CUARTA ETAPA (1990).

LA INSTITUCIONALIZACIÓN UNIVERSITARIA: LA DIPLOMATURA EN RELACIONES LABORALES

QUINTA ETAPA (2000).
LA CONSOLIDACIÓN DE LAS CIENCIAS LABORALES: LA LICENCIATURA EN CIENCIAS DEL
TRABAJO

Fuente.- Elaboración propia

LAS SALIDAS PROFESIONALES (PERFILES PROFESIONALES)

Esta evolución en el tiempo ha conllevado la profesionalización de la actividad, reubicando al técnico en relaciones laborales en el mercado de trabajo. Las competencias profesionales de estos egresados han ido ampliándose de manera que sus posibilidades de inserción laboral cada vez han sido más y más variadas. En el año 
2005, la ANECA -Agencia Nacional de Evaluación de la Calidad y Acreditación- en cumplimiento del proceso de convergencia europea de educación superior (más conocido como Plan Bolonia o EEES: Espacio Europeo para la Educación Superior) publicaba el Libro Blanco sobre el Título de Grado en Ciencias Laborales y Recursos Humanos, cuyo contenido proponía, a partir de un macroestudio sobre la evolución de la inserción laboral de los diplomados en Relaciones Laborales en el período $1997 / 2002$, un listado de las posibles salidas profesionales naturales para estos egresados, denominados en la guía perfiles profesionales (ver tabla 2), así como también se describía el esqueleto de competencias -genéricas y específicas- que a la postre iban a formar parte de la parrilla de competencias del nuevo título de Grado en Relaciones Laborales y Recursos Humanos.

\section{Tabla 2. Perfiles Profesionales Grado Relaciones laborales y Recursos Humanos}

1) GRADUADO SOCIAL

2) DIRECCIÓN Y GESTIÓN DE RECURSOS HUMANOS

3) PREVENCIÓN DE RIESGOS LABORALES

4) GESTIÓN, MEDIACIÓN E INTERVENCIÓN EN EL MERCADO DE TRABAJO: AGENTES DE EMPLEO Y DESARROLLO LOCAL (AEDL)

5) AUDITORÍA SOCIOLABORAL

6) ENSEÑANZA

7) ADMINISTRACIONES PÚBLICAS

Fuente.- Aneca (2005)

El estudio trataba de recoger la situación de estos estudios acorde a la realidad con la que se encontraban $-\mathrm{O}$ al menos se podían encontrar- los futuros egresados. Junto a las salidas tradicionales de estos estudios, el ejercicio de la profesión de Graduado Social como ejerciente libre o la de responsable de las relaciones laborales en el seno de una empresa, se abrían otras orientaciones profesionales en las que ejercer las competencias, destrezas y habilidades que unos estudios de estas características podían proporcionar. Aspectos vinculados con la prevención de riesgos laborales, la auditoría del sistema socio-laboral, las políticas de empleo o la enseñanza en todos sus niveles se estaban convirtiendo en nuevos nichos profesionales emergentes para estos titulados. En la tabla 
3 podemos observar el grado de inserción laboral de los titulados en Ciencias Laborales según los distintos perfiles profesionales descritos ${ }^{6}$.

Tabla 3. Inserción laboral Titulados en Ciencias laborales Según Perfiles Profesionales

1) GRADUADO SOCIAL

$19,8 \%$

2) DIRECCIÓN Y GESTIÓN DE RECURSOS HUMANOS

$20,2 \%$

3) PREVENCIÓN DE RIESGOS LABORALES

$3,5 \%$

4) GESTIÓN, MEDIACIÓN E INTERVENCIÓN EN EL MERCADO DE TRABAJO: AGENTES DE EMPLEO Y DESARROLLO LOCAL (AEDL)

$3,7 \%$

5) AUDITORÍA SOCIOLABORAL

$0,8 \%$

6) ENSEÑANZA

$2,2 \%$

7) ADMINISTRACIONES PÚBLICAS

$0,8 \%$

OTROS

$24,0 \%$

ADMINISTRATIVOS

$25,0 \%$

Fuente.- Aneca (2005)

LA HIPÓTESIS CENTRAL DE ESTE ARTíCULO

Partiendo de la realidad descrita, en la que la de Agente de Empleo y Desarrollo Local es una de las siete salidas profesionales establecidas para los egresados en Ciencias Laborales, y teniendo en cuenta que no aparece recogido de manera explícita como perfil profesional en ninguna otra titulación -en la tabla 4 presentamos las salidas y perfiles profesionales de los Grados en Economía, Derecho y Psicología, como titulaciones muy vinculadas-, la hipótesis central de este artículo girará entorno a la cuestión de, ¿por qué existiendo una titulación como la diplomatura en RRLL y su continuación natural, la licenciatura en Ciencias del Trabajo, que entre sus perfiles

6. Según el estudio de la Aneca, por la dificultad que entrañó su categorización, se añaden dos categorías más a la clasificación: otros y administrativos. 
profesionales tiene definido uno en concreto de gestión, mediación e intervención en el mercado de trabajo (AEDL), nos encontramos con niveles tan bajos de presencia de estos egresados en esta actividad?

Tabla 4. Salidas y Perfiles Profesionales

\begin{tabular}{|c|c|c|}
\hline $\begin{array}{l}\text { GRADO EN } \\
\text { ECONOMİA }\end{array}$ & GRADO EN DERECHO & $\begin{array}{l}\text { GRADO EN } \\
\text { PSICOLOGÍA }\end{array}$ \\
\hline $\begin{array}{l}\text { 1. Servicios de estudios y } \\
\text { planificación } \\
\text { 2. Fiscalidad } \\
\text { 3. Administración pública } \\
\text { 4. Organismos interna- } \\
\text { cionales } \\
\text { 5. Comercio Exterior } \\
\text { 6. Dirección o gerencia } \\
\text { de empresas } \\
\text { 7. Consultoría económica } \\
\text { 8. Docencia e Investiga- } \\
\text { ción }\end{array}$ & $\begin{array}{l}\text { 1. Abogado. Procurador } \\
\text { 2. Notario, registrador } \\
\text { 3. Funcionario de administración de jus- } \\
\text { ticia: juzgados de } 1^{a} \text { instancia, ministerio } \\
\text { fiscal, tribunales superiores y secretarios } \\
\text { de juzgado } \\
\text { 4. Funcionario de administraciones pú- } \\
\text { blicas. Escala superior (abogado del } \\
\text { estado, TAC, etc.) } \\
\text { 5. Funcionario de administraciones pú- } \\
\text { blicas. Escala media (administraciones } \\
\text { central, territorial y local) } \\
\text { 6. Funcionario de organizaciones inter- } \\
\text { nacionales (UE, OTAN, ONU, etc.) } \\
\text { 7. Empresa privada (banca, gran empre- } \\
\text { sa, pymes y asesorías/consultorías) } \\
\text { 8. Asociaciones y organizaciones no } \\
\text { públicas (sindicatos, ONG y otras aso- } \\
\text { ciaciones) }\end{array}$ & $\begin{array}{l}\text { 1. Psicología Clínica } \\
\text { 2. Psicología de la Edu- } \\
\text { cación } \\
\text { 3. Psicología del Trabajo, } \\
\text { las Organizaciones y los } \\
\text { Recursos Humanos } \\
\text { 4. Psicología de la Inter- } \\
\text { vención social y comuni- } \\
\text { taria }\end{array}$ \\
\hline
\end{tabular}

Fuente.-Elaboración propia

Para intentar responder a esta cuestión, basándonos en informaciones y datos procedentes de la investigación que sustenta este artículo, en los apartados siguientes presentaremos los orígenes y el proceso seguido por el empleo y el desarrollo local hasta posicionarse como una profesión, así como su evolución en número en el ámbito geográfico de la Comunitat Valenciana. A continuación, realizaremos una aproximación en datos a la evolución de la presencia de egresados en Ciencias Laborales en desarrollo local, para así finalmente proponer los principales factores que consideramos han determinado esta evolución. 


\section{LA CONFIGURACIÓN DEL DESARROLLO LOCAL COMO PROFESIÓN}

La segunda mitad de la década de los ochenta trajo consigo la instauración de una nueva figura técnica a nivel local, el Agente de Empleo y Desarrollo Local -más conocido como AEDL, o simplemente ADL. Los efectos tardíos sobre la realidad española de la crisis mundial acaecida diez años antes, cuestionaron la viabilidad de las actuaciones para el desarrollo según la metodología utilizada hasta el momento. Modelo con una concepción centrada en lo universal como solución, en donde las políticas macro se entendían como aplicables, y por tanto útiles en cualquier territorio y en cualquier situación, convirtiéndose en la herramienta central de su actuación. La no adecuación de estas medidas macro sobre la nueva realidad dibujada en el tejido empresarial y especialmente en lo concerniente al empleo, pues no alcanzaron ni los resultados esperados ni la tan ansiada reactivación de la economía, dejó el camino libre a un nuevo planteamiento: la definición de las actuaciones desde la base.

La responsabilidad de las políticas macro pasó desde ahora a lo micro, siendo el nivel municipal el que recogió el testigo directo de luchar contra la crisis y sus efectos sobre el territorio y la población. Lo local cobró sentido propio, conceptualizándose como el espacio idóneo para la implementación de actuaciones.

Como hemos adelantado, esta nueva manera de hacer, apostó por la necesidad de una nueva figura en la lucha contra el desempleo. Aparecieron así los Agentes de Empleo y Desarrollo Local (AEDL), técnicos que concebidos como trabajadores de las corporaciones locales o entidades dependientes o vinculadas a una Administración local se les encomendaba como misión principal colaborar en la promoción e implantación de las políticas activas de empleo relacionadas con la creación de actividad empresarial, desarrollándose dicha colaboración en el marco de actuación conjunta y acordada de la entidad contratante y en aquel momento, el Instituto Nacional de Empleo $^{7}$. A rasgos generales nacía un nuevo profesional al servicio del municipio, al que para cumplir con el objetivo encomendado, se le asignan las siguientes funciones:

1. Prospección de recursos ociosos o infrautilizados, de proyectos empresariales de promoción económica local e iniciativas innovadoras para la generación de empleo en el ámbito local, identificando nuevas actividades económicas y posibles emprendedores.

\footnotetext{
7. Texto del artículo 7 de la Orden de 15 de julio de 1999 del Ministerio de Trabajo y Asuntos Sociales sobre "Fomento del Desarrollo Local e impulso de los proyectos y empresas calificadas como I+E" (Modificada parcialmente por la Orden de 27 de diciembre de 1999, por la Orden 49/2005, de 14 de enero y recientemente por la Orden TAS/360/2008, de 6 de febrero).

8. Texto del artículo 8 de la citada Orden.
} 
2. Difusión y estímulo de potenciales oportunidades de creación de actividad entre los desempleados, promotores y emprendedores, así como instituciones colaboradoras.

3. Acompañamiento técnico en la iniciación de proyectos empresariales para su consolidación en empresas, los proyectos generadores de nuevos empleos, asesorando e informando sobre la viabilidad técnica, económica y financiera y, en general, sobre los planes de lanzamiento de las empresas.

4. Apoyo a promotores de las empresas, una vez constituidas éstas, acompañando técnicamente a los mismos durante las primeras etapas de funcionamiento, mediante la aplicación de técnicas de consultoría en gestión empresarial y asistencia en los procesos formativos adecuados para coadyuvar a la buena marcha de las empresas creadas.

5. Cualesquiera otras que contribuyan a la promoción e implantación de políticas activas de empleo e impulse la creación de actividad empresarial.

\section{AEDL: Una Realidad Sobre el Territorio}

Esta nueva figura de actuación contra la crisis, que en la década de los ochenta apareció como una iniciativa más para el empleo, veinticinco años después se ha convertido en la pieza clave del modelo de desarrollo económico implantado. Dicha evolución la podemos ver reflejada en la siguiente tabla, donde se observa el proceso de aparición de todos estos técnicos.

Tabla 5. Evolución Número de Aedl C.V. (1985-2008)

\section{NÚMERO AEDL}

\begin{tabular}{|l|}
\hline 1985 \\
\hline 1990 \\
\hline 1995 \\
\hline 2000 \\
\hline 2005 \\
\hline 2008 \\
\hline
\end{tabular}

\begin{tabular}{|c|}
\hline 14 \\
\hline 48 \\
\hline 95 \\
\hline 211 \\
495 \\
\hline 610 \\
\hline
\end{tabular}

Fuente.-Adlypse

El proceso de implantación de estos nuevos técnicos en el territorio nos da buena muestra de cómo se ha ido generalizando la posibilidad de que un municipio disponga de un técnico subvencionado que desarrolle todas estas funciones. En la 
tabla 6 aportamos datos sobre el número de Ayuntamientos con un servicio de AEDL propio -y por tanto con al menos un técnico en plantilla-, así como del alcance de la actividad de éstos, manifestada en la tasa de cobertura poblacional que adquiere el modelo.

Tabla 6. Evolución del Modelo de Desarkollo C. V. (1985-2008)

\begin{tabular}{|c|c|c|c|}
\hline & № AEDL & $\begin{array}{c}\text { № DE POBLACIONES } \\
\text { CON SERVICIO DE } \\
\text { AEDL }\end{array}$ & $\begin{array}{l}\text { TASA DE COBERTURA } \\
\text { DE LA POBLACIÓN }\end{array}$ \\
\hline 1985 & 14 & 9 & $14,42 \%$ \\
\hline 1990 & 48 & 41 & $21,30 \%$ \\
\hline 1995 & 100 & 89 & $33,74 \%$ \\
\hline 2000 & 211 & 165 & $52,90 \%$ \\
\hline 2005 & 495 & 293 & $65,77 \%$ \\
\hline 2008 & 610 & 401 & $87,21 \%$ \\
\hline
\end{tabular}

Fuente.- Elaboración propia y Adlypse

4. LA EVOLUCIÓN DEL TITULADO EN CIENCIAS LABORALES EN EL DESARROLLO LOCAL: UNA APROXIMACIÓN EN DATOS

Una vez expuesta la evolución de la actividad del desarrollo local, cabe analizar cómo ha sido la incorporación de los profesionales de las Ciencias Laborales a este campo, si bien los factores que han dificultado los analizaremos en el apartado posterior. Tres tablas más un gráfico ilustran la mencionada evolución. En primer lugar la realidad actual de la titulación de procedencia del técnico AEDL, y entre ellos la posición que ocupan los titulados en Ciencias Laborales; en segundo lugar, la evolución del número de técnicos AEDL procedentes de titulaciones vinculadas con las Ciencias Laborales, con una comparativa con el número total de técnicos existentes y su representatividad; y en tercero y último lugar, una tabla y un gráfico en la que presentamos datos de la evolución de las titulaciones que poseen los técnicos AEDL en los últimos veinte años, tanto en cantidad como en representatividad.

Un punto de partida para nuestra aproximación a la situación actual de la presencia de los titulados en Ciencias Laborales en el desarrollo local nos la muestra la tabla 7 , donde aparece reflejada la representatividad actual que ostentan cada una de las titulaciones de origen de los técnicos AEDL participantes en la investigación. 
Tabla 7. Titulación Académica Aedl (2008)

\section{LICENCIATURA EN PSICOLOGIA}

LICENCIATURA EN DERECHO

LICENCIATURA EN ECONÓMICAS-ADE

DIPLOMATURA EN RRLL-CC. DEL TRABAJO

LICENCIATURA EN GEOGRAFIA E HISTORIA

DIPLOMATURA TRABAJO SOCIAL

DIPLOMATURA EN EMPRESARIALES

LICENCIATURA EN SOCIOLOGÍA

DIPLOMATURA EN TURISMO

OTROS ESTUDIOS (ARQUITECTURA TÉCNICA, LOGOPEDIA,

FARMACIA, PEDAGOGIA, PUBLICIDAD Y RELACIONES PÚBLICAS,

PERIODISMO, INGENIERIA AGRÓNOMOS, ETC..)

\begin{tabular}{|l|}
\hline $20,89 \%$ \\
\hline $19,40 \%$ \\
\hline $18,66 \%$ \\
\hline $16,88 \%$ \\
\hline $6,72 \%$ \\
\hline $5,22 \%$ \\
\hline $3,73 \%$ \\
\hline $1,49 \%$ \\
\hline $1,49 \%$ \\
\hline
\end{tabular}

Fuente.- Elaboración propia

Por su parte la tabla 8 se centra en el número de técnicos AEDL que son titulados en Ciencias Laborales, presentando datos de su evolución en las dos últimas décadas. A su vez compara esta evolución con el número total de técnicos en la Comunitat Valenciana, aportando un porcentaje de su representatividad en cada momento, lo que nos permite de alguna manera cuantificar su crecimiento y su presencia real en la actividad y en el territorio.

Tabla 8. Evolución Número De Aedl Titulados En Cc. Laborales (1985-2008)

\begin{tabular}{|c|c|c|c|}
\hline & NÚMERO AEDL'S & $\begin{array}{c}\text { No TITULADOS } \\
\text { EN CIENCIAS } \\
\text { LABORALES }\end{array}$ & REPRESENTATIVIDAD \\
\hline 1985 & 14 & 0 & $0,00 \%$ \\
\hline 1990 & 48 & 1 & $2,05 \%$ \\
\hline 1995 & 100 & 4 & $4,00 \%$ \\
\hline 2000 & 211 & 16 & $7,58 \%$ \\
\hline 2005 & 495 & 72 & $14,54 \%$ \\
\hline 2008 & 610 & 103 & $16,88 \%$ \\
\hline
\end{tabular}

Fuente.- Elaboración propia y Adlypse 
Por su parte las tablas 9 y 10, nos muestran de una manera documental y gráfica, el proceso de evolución sufrido por las principales titulaciones con las que cuentan los técnicos AEDL en cada momento, así como su representatividad total.

Tabla 9 . Evolución Titulaciones en Desarrollo local (1985-2008)²

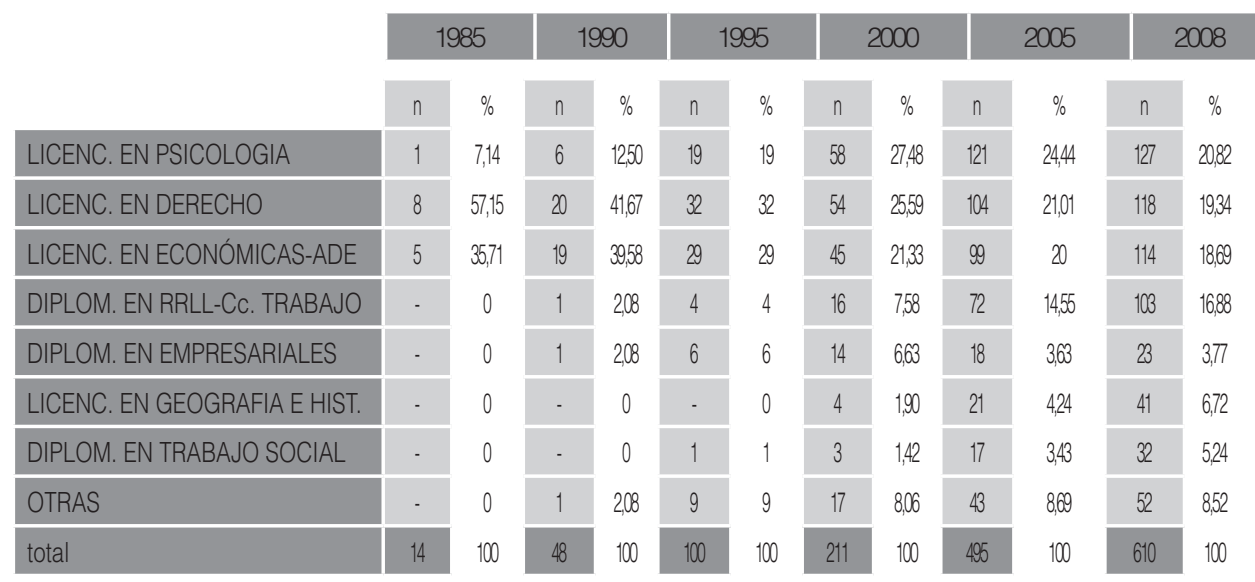

Fuente .- Elaboración propia

Tabla 10 . Evolución Titulaciones en Desarrollo Local (1985-2008)

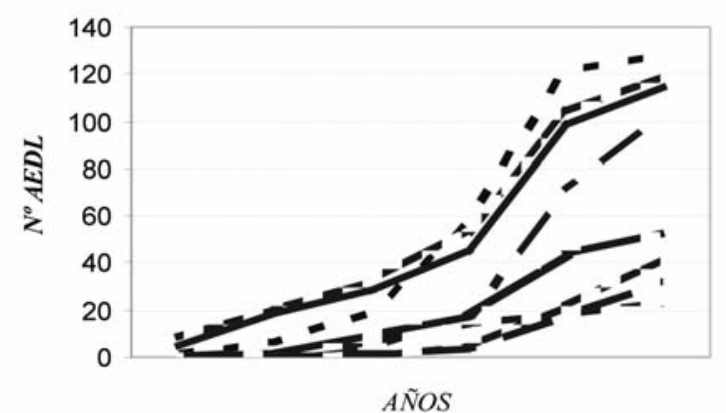

$A \tilde{N} O S$
- - 'LIC. EN PSICOLOGIA

-—LIC. EN DERECHO

LIC. EN ECO-ADE

- - DIPL. EN RRLL-Cc TRAB.

- - DIPL. EN EMPRESAR.

-ーー-LIC. EN GEOGR. E HIST.

- DIPL. TRAB. SOCIAL

OTRAS 


\section{UNA PROPUESTA DE FACTORES DETERMINANTES}

¿Qué factores son los que han causado una evolución como la expuesta en el apartado anterior? Proponemos a continuación una serie de dimensiones a tener en cuenta en este proceso, y ello lo haremos en base a cinco grandes agrupaciones en las que hemos clasificado estos factores. Concretamente son las siguientes:

1. Factores relacionados con el modelo de desarrollo local.

2. Factores relacionados con el modelo educativo.

3. Factores relacionados con el contexto propio de la actividad desarrollada por los técnicos AEDL.

4. Factores relacionados con la juventud de la actividad.

5. Factores relacionados con la entidad responsable del empleo y el desarrollo local.

En el primer grupo, aquellas relacionadas directamente con el modelo de desarrollo local implantado, ponen de manifiesto las dificultades inherentes planteadas por dicho modelo: una excesiva orientación originaria del modelo hacia la obtención rápida de resultados, en forma de creación de puestos de trabajo - por cuenta propia o por cuenta ajena, lo que generó una actividad "mercantilizada" por parte del modelo, que se ha centrado en demasía en lo económico -cifras y datos- dejando en muchas ocasiones de lado lo social -personas y comunidades. Si a ello añadimos una dificultad estructural inicial importante, como es que el puesto de AEDL parecía estar pensado para un Licenciado/a, quedando vetada a todos aquellos egresados que no alcanzaban este nivel. Ello posibilitó que las titulaciones demandadas en origen fueran básicamente dos: Derecho y Económicas (ver tabla 9).

En segundo lugar, dificultades relacionadas con el modelo en este caso educativo. Como exponíamos en los apartados anteriores, las Ciencias Laborales son estudios muy recientes en el tiempo, de gran desconocimiento social, que además han sufrido numerosos cambios en su denominación -de Estudios Sociales a Graduado Social, y posteriormente a Relaciones Laborales. A su vez es destacable la orientación natural de los estudiantes de Ciencias Laborales hacia salidas relacionadas con los recursos humanos, las relaciones laborales o la asesoría jurídico-laboral, además de que todas ellas salidas en la esfera de la empresa privada (ver tablas 3 y 11).

Tabla 11. Tipo de Empresa al Terminar los Estudios

\begin{tabular}{l} 
ADMINISTRACION PUBLICA \\
EMPRESA PRIVADA \\
DESPACHO PROFESIONAL \\
OTROS \\
\hline
\end{tabular}

\begin{tabular}{|l|}
\hline $14,7 \%$ \\
\hline $74,9 \%$ \\
\hline $3,6 \%$ \\
\hline $6,8 \%$ \\
\hline
\end{tabular}

Fuente.- Aneca (2005) 
En tercer lugar, factores relacionados con el contexto propio de la actividad del Agente de Empleo y Desarrollo Local. Entre ellos destaca por encima del resto la insuficiente descripción del puesto de AEDL, que a lo largo de estos veinticinco años de funcionamiento se ha ido creando a sí mismo, careciendo de unas directrices claras en las que basarse. La no implicación pública en la concreción de la actividad, han posibilitado que la persona ocupante del puesto lo autoconfigurase desde su práctica profesional del día a día. Por tanto no se ha definido competencialmente un puesto de trabajo, sino que el puesto se ha ido moldeando en función de las competencias concretas de la persona que lo ocupaba. Otra manifestación de la escasa implicación pública en la materia es la permisividad existente en lo referente a las titulaciones habilitadas para el ejercicio de la actividad. Se ha tratado de un proceso en el que se ha permitido la entrada de titulados con orígenes muy variopintos (ver tabla 7).

Otro grupo de factores, se centraría principalmente en torno a la juventud de la actividad. Hay que tener muy presente que se trata de una ocupación que acaba de cumplir su mayoría de edad como tal, que si bien sus inicios oficialmente se remontan a mitades de la década de los ochenta, no es hasta avanzados los noventa cuando realmente se generaliza el mismo (ver tabla 5).

Por último, un grupo de factores dirige su atención hacia la entidad que gestiona la figura del técnico AEDL como fuente de resistencias a este proceso. En el caso valenciano el SERVEF -Servicio Valenciano para el Empleo y la Formación-, es el organismo heredero de las competencias del INEM y por tanto responsable de las políticas activas para el empleo. Dificultades generadas en el propio proceso de contratación, donde como hemos mencionado con una clara orientación hacia estudios universitarios de licenciatura -principalmente Derecho o Económicas- no facilitaban este proceso. Junto a ello, un claro desconocimiento de la existencia y de las competencias que podían generar los estudios en Relaciones Laborales, lo que pone de manifiesto la descoordinación existente entre la Autoridad Laboral -competente en materia de Desarrollo Local y Empleo- y la Autoridad Educativa -competente en materia universitaria. Una vez más se manifiesta la escasa implicación oficial con la titulación.

\section{CONCLUSIONES: UN FUTURO ESPERANZADOR}

Al igual que les está ocurriendo a los estudios en Ciencias Laborales en muchos otros campos, en el desarrollo local también podemos observar cómo ha mejorado su situación con el transcurso de los años. Tres están siendo a nuestro entender los facilitadores fundamentales de este proceso:

1. En primer lugar, el desarrollo local se ha convertido en un yacimiento de empleo para muchos nuevos egresados, entre ellos claro está también para los titulados en Ciencias Laborales. Empleos directos a los que nos hemos 
referido en el presente artículo, como el de Agente de Empleo y Desarrollo Local, pero también empleos indirectos como técnicos de apoyo que operan a su vez en el campo de las políticas de empleo y desarrollo local (ejemplos como formadores, orientadores, y un largo etcétera).

2. En segundo lugar, la dinámica implementada en el modelo de desarrollo local claramente ha cambiado, abriendo el abanico de posibles candidatos a acceder a estos puestos, lo que ha beneficiado claramente a los titulados en Ciencias Laborales.

3. Por último, el mero transcurso del tiempo, que ha permitido que los estudios en Ciencias Laborales se conozcan más y mejor. Con los estudios de nivel superior en Ciencias Laborales, la mejora de la imagen -prestigio- del titulado en Ciencias Laborales ha sido una realidad, dejando de ser tan sólo un mero administrativo de personal pasando a ser considerado como un profesional con posibilidades laborales mucho más amplias. Un claro ejemplo es el reconocimiento universitario a estos titulados permitiéndoles acceder a la docencia universitaria, así cómo a campos de la investigación sociolaboral donde hasta el momento no eran admitidos.

Pese a que en los últimos años, la integración de titulados en Relaciones Laborales y Ciencias del Trabajo en el campo del desarrollo local ha sido una realidad, estamos en condiciones de afirmar que no ha alcanzado todavía sus niveles máximos, sino que la potencialidad de estos egresados, con una formación específica en materias tan aplicables en esta actividad todavía puede generar efectos más positivos sobre ella, posicionando de mejor manera a estos técnicos.

\section{REFERENCIAS BIBLIOGRÁFICAS}

ANECA (2005), Libro Blanco del Título de Grado en Ciencias Laborales y Recursos Humanos. [Disponible en http://www.aneca.es/modal_eval/docs/libroblanco_rrhh_def.pdf]

ANECA (2005), Libro Blanco del Título de Grado en Economía y Empresa. [Disponible en http://www.aneca.es/media/150292/libroblanco_economia_def.pdf]

ANECA (2006), Libro Blanco del Título de Grado en Derecho. [Disponible en http:// www.aneca.es/media/150240/libroblanco_derecho_def.pdf]

ANECA (2005), Libro Blanco del Título de Grado en Psicología. [Disponible en http:// www.aneca.es/media/150356/libroblanco_psicologia_def.pdf]

Galán García, A (ed.) (1998) La enseñanza en las Relaciones Laborales. Huelva, Servicio de Publicaciones de la Universidad de Huelva. 
Lerma Montero, I. (2005): "Grado en ciencias laborales y recursos humanos", en Trabajo: Revista andaluza de relaciones laborales, $n^{\circ} 15$, pp. 143-173

Sempere Navarro, A. V. (1998): "Formación universitaria y salidas profesionales", en Acciones e investigaciones sociales, No 8 (Ejemplar dedicado a: Actas de las Jornadas sobre Nuevos Empleos, Nuevas Empresas, Nuevas Relaciones Laborales: Zaragoza, del 13 al 16 de mayo de 1998 / Escuela Universitaria de Estudios Sociales (dir. congr.)) , pp. 285-300 
